\title{
HUBUNGAN PELAKSANAAN PROGRAM KESEHATAN DAN KESELAMATAN KERJA DENGAN KINERJA KARYAWAN BAGIAN TAMBANG
}

\author{
Herlinawati*Hayyatun Nubus**
}

\begin{abstract}
ABSTRAK
Berdasarkan hasil dari data kinerja karyawan PT. Arteria Daya Mulia (ARIDA) Cirebon pada bulan Juni tahun 2015 menunjukkan output kerja atau pencapaian kerja masih kurang dari target yang diharapkan maka hasil produksi perhari belum menunjukkan kinerja yang baik yang dimungkinkan dipengaruhi oleh faktor internal organisasi, yaitu program kesehatan dan keselamatan kerja dimana pelaksanaan program kesehatan dan keselamatan kerja yang masih kurang baik sehingga kinerja karyawannya pun kurang baik. Tujuan penelitian ini adalah untuk mengetahui hubungan pelaksanaan program kesehatan dan keselamatan kerja dengan kinerja karyawan bagian tambang di PT. Arteria Daya Mulia (ARIDA) Cirebon Tahun 2015. Rancangan dalam penelitian ini adalah Cross Sectional. Populasi penelitian ini adalah seluruh karyawan bagian tambang di PT. Arteria Daya Mulia (ARIDA) Cirebon Tahun 2015 sebanyak 112 karyawan. Jumlah sampel sebanyak 52 karyawan yang diambil secara Simple Random Sampling. Metode pengumpulan data menggunakan cara angket. Data dianalisis secara statistik menggunakan Uji Chi-Square pada taraf kepercayaan 5\% (0,05). Hasil uji statistik dengan menggunakan uji Chi-Square diperoleh nilai $\mathrm{P}$ value $=0,020$ pada taraf kepercayaan $5 \%$ karena nilai $\mathrm{P}$ value $=0,020$ lebih kecil dari $0,05(0,020 \leq 0,05)$. Sehingga Ha diterima yang menyatakan ada hubungan antara pelaksanaan program kesehatan dan keselamatan kerja dengan kinerja karyawan bagian tambang PT. Arteria Daya Mulia (ARIDA) Cirebon Tahun 2015.
\end{abstract}

Kata Kunci : Kesehatan Keselamatan Kerja, Kinerja Karyawan

\begin{abstract}
Based on the results of the performance data of employees of PT. Arteria Daya Mulia (ARIDA) Cirebon in June 2015 shows the output of work or achievement of work is still less than the expected target, the production day has not shown good performance enabled influenced by factors internal to the organization, a program of health and safety where implementation of the program occupational health and safety are still not good so the performance was less good employees. The purpose of this study was to determine the relationship of the program with the occupational health and safety performance in the mining section of employees of PT. Arteria Daya Mulia (ARIDA) Cirebon 2015. The design of this study was cross sectional. The study population is all employees of the mine in PT. Arteria Daya Mulia (ARIDA) Cirebon in 2015 as many as 112 employees. The total sample of 52 employees who were taken by simple random sampling. Methods of data collection using the questionnaire method. Date were statistically analyzed using Chi-Square test at the level of 5\% (0.05). Results of statistical test by using Chi-Square test values obtained $\mathrm{P}$ value $=0.020$ confidence level of $5 \%$ since the value $\mathrm{P}$ value $=0.020$ less than $0.05(0.05 \leq 0.020)$. So Ha is received stating there is a relationship between the implementation of occupational health and safety program with employee performance of the mining PT. Arteria Daya Mulia (ARIDA) Cirebon 2015.
\end{abstract}

Keywords: Health Safety at Work, Employee Performance

\footnotetext{
* Staf Pengajar PSKM STIKes Cirebon

** Alumni PSKM STIKes Cirebon Lulus Tahun 2015
} 


\section{PENDAHULUAN}

Perusahaan yang mempekerjakan tenaga kerja dan mempunyai potensi bahaya yang ditimbulkan oleh proses produksi yang dapat mengakibatkan kecelakaan kerja seperti peledakan, kebakaran, pencemaran dan penyakit akibat kerja, wajib menerapkan kesehatan dan keselamatan kerja. Berdasarkan PEMNAKER 05/MEN/1996 dan mengacu pada Undangundang No. 1 tahun 1970 tentang kesehatan dan keselamatan kerja dapat dijadikan acuan bagi perlindungan tenaga kerja dari bahaya kecelakaan dan penyakit akibat bekerja maupun akibat lingkungan kerja. ${ }^{1}$

Program kesehatan dan keselamatan kerja adalah suatu sistem program yang dibuat bagi pekerja maupun pengusaha sebagai upaya pencegahan timbulnya kecelakaan kerja dan penyakit akibat hubungan kerja dalam lingkungan kerja dengan cara mengenali hal-hal yang berpotensi menimbulkan kecelakaan kerja serta tindakan antisipatif bila terjadi hal demikian. ${ }^{1}$

Kesehatan dan keselamatan kerja merupakan hal yang penting bagi perusahaan, karena dampak kecelakaan kerja atau penyakit akibat hubungan kerja tidak hanya merugikan karyawan, tetapi juga perusahaan. Perusahaan harus menanggung biaya pengobatan dan biaya rumah sakit atau bahkan menanggung biaya penguburan jika korban meninggal dunia, hilangnya waktu kerja karyawan yang menjadi korban dan rekan-rekan karyawan yang ikut menolong sehingga menghambat kelancaran kerja, merekrut karyawan baru dan memberi pelatihan dan juga dapat menurunkan mental atau kondisi psikis para karyawan lainnya. Sedangkan kerugian yang terjadi bagi karyawan adalah karyawan dapat mengalami luka-luka, cacat fisik dan meninggal dunia. ${ }^{1}$

PT. Arteria Daya Mulia (ARIDA) adalah sebuah perusahaan yang memproduksi jaring ikan, benang, tambang, benang nilon dan serat nilon sebagai bahan bakunya. Saat ini PT. Arteria Daya Mulia (ARIDA) telah melakukan pemasaran dengan produksi tambang plastik namun dengan kapasitas tambang plastik yang masih relatif rendah. ${ }^{2}$

Tambang merupakan salah satu bagian produksi yang ada di PT. Arteria Daya Mulia (ARIDA). Proses produksi bagian tambang memakai bahan baku dari bagian Extruder berupa benang monofilament dan polyethylene. Produk yang dihasilkan disalurkan ke bagian produksi lain. Bagian tambang terdiri 3 seksi, yaitu seksi Extruder PE, Twisting PE, Tambang. ${ }^{3}$

Berdasarkan data dari PT. Arteria Daya Mulia (ARIDA) program kesehatan dan keselamatan kerja belum berjalan dengan maksimal atau masih dalam proses perbaikan, khususnya di bagian tambang masih terdapat banyak kecelakaan kerja yang terjadi setiap tahunnya di tempat kerja. Di bagian tambang tidak semua kecelakaan kerja dilaporkan atau dicatat oleh tim Panitia Pembina Kesehatan dan Keselamatan Kerja (P2K3) misalnya jari tergores Cutter, kaki terbentur mesin. Penggunaan dan penyediaan alat pelindung diri untuk karyawan yang belum maksimal. ${ }^{3}$

Berdasarkan data yang didapat pada tanggal 15 Juni 2015 menunjukkan bahwa hasil produksi bagian tambang perhari di seksi Extruder PE menghasilkan $4.440 \mathrm{Kg}$ tambang dari target $4.650 \mathrm{Kg}$ tambang perhari. Seksi Twisting $P E$ menghasilkan $1.150 \mathrm{Kg}$ tambang dari target $1.424 \mathrm{Kg}$ tambang perhari. Seksi Tambang menghasilkan $1.933 \mathrm{Kg}$ tambang dari target $2.012 \mathrm{Kg}$ tambang perhari. ${ }^{3}$ Maka dengan data tersebut menunjukkan hasil produksi perhari belum menunjukkan kinerja yang baik karena output kerja atau pencapaiannya masih kurang dari target yang diharapkan. ${ }^{3}$

Penelitian yang dilakukan Catarina Cori P. P tahun 2012 tentang pengaruh keselamatan dan kesehatan kerja terhadap prestasi kerja karyawan PT. PLN (Persero) APJ Semarang, keselamatan dan kesehatan kerja berpengaruh signifikan terhadap motivasi kerja. Besar pengaruh yang diberikan variabel keselamatan dan kesehatan kerja terhadap motivasi kerja 58,9\%. Keselamatan dan kesehatan kerja berpengaruh positif dan signifikan terhadap prestasi kerja 
karyawan PT. PLN (Persero) APJ Semarang. Besar pengaruh yang diberikan variabel keselamatan dan kesehatan kerja terhadap prestasi kerja $62 \% .^{4}$

Tujuan Penelitian ini untuk mengetahui hubungan pelaksanaan program kesehatan dan keselamatan kerja terhadap kinerja karyawan bagian tambang di PT. Arteria Daya Mulia (ARIDA) Cirebon tahun 2015.

\section{METODOLOGI PENELITIAN}

Penelitian ini merupakan penelitian penjelasan (Explanatory Research) menggunakan metode survey dengan pendekatan cross-sectional. ${ }^{5}$ Dalam penelitian ini yang menjadi variabel independen adalah pelaksanaan program kesehatan dan keselamatan sedangkan variabel dependen adalah kinerja karyawan.

Populasi dalam penelitian ini adalah seluruh karyawan bagian tambang di PT. Arteria Daya Mulia (ARIDA) Cirebon sebanyak 112 karyawan diambil dari data pada bulan Mei Tahun 2015. Berdasarkan perhitungan rumus besar sampel di dapatkan sampel sejumlah 52 orang dan cara pengambilan sampel dengan simple random sampling dengan cara undian. Instrumen dalam penelitian ini adalah kuesioner. Data primer dalam penelitian ini diperoleh dengan menggunakan cara angket. Analisis data dilakukan melalui analisis univariat dengan menyajikan distribusi frekuensi dan persentase dari tiap variabel. ${ }^{6}$ Sedangkan analisis bivariat yaitu untuk mencari hubungan variabel bebas atau program kesehatan dan keselamatan kerja dan variabel terikat atau kinerja karyawan dengan dengan taraf nyata $5 \%$.

\section{HASIL PENELITIAN}

\section{Pelaksanaan Program Kesehatan Dan Keselematan Kerja}

Tabel 1. Distribusi Frekuensi Pelaksanaan Program Kesehatan Dan Keselematan Kerja Bagian Tambang

\begin{tabular}{llccc}
\hline \multirow{2}{*}{ No } & Program Kesehatan & Dan & Frekuensi & Persentase (\%) \\
& Keselematan Kerja & & 28 & 53.8 \\
\hline 1 & Kurang Baik & 24 & 46.2 \\
2 & Baik & 52 & 100 \\
\hline
\end{tabular}

Tabel 1 menunjukkan sebagian responden $(53,8 \%)$ menyatakan pelaksanaan program kesehatan dan keselamatan kerja kurang baik.

\section{Kinerja Karyawan}

Tabel 2 Distribusi Frekuensi Kinerja Karyawan Bagian Tambang

\begin{tabular}{llcc}
\hline \multirow{2}{*}{ No } & Kinerja Karyawan & Frekuensi & Persentase $(\%)$ \\
\hline 1 & Kurang Baik & 41 & 78.8 \\
2 & Baik & 11 & 21.2 \\
\hline & Jumlah & 52 & 100 \\
\hline
\end{tabular}

Tabel 2 menunjukkan sebagian besar responden $(78,8 \%)$ memiliki kinerja kurang baik 


\section{Hubungan Pelaksanaan Program Kesehatan Dan Keselamatan Kerja Dengan Kinerja Karyawan}

Tabel 3. Hubungan Pelaksanaan Program Kesehatan Dan Keselamatan Kerja Dengan Kinerja Karyawan Bagian Tambang.

\begin{tabular}{|c|c|c|c|c|c|c|c|c|}
\hline \multirow{3}{*}{ No } & Pelaksanaan & \multicolumn{4}{|c|}{ Kinerja } & \multirow{2}{*}{\multicolumn{2}{|c|}{ Total }} & \multirow{2}{*}{$\mathrm{P}$ value } \\
\hline & \multirow{2}{*}{$\begin{array}{l}\text { Program Kesehatan } \\
\text { Dan Keselamatan } \\
\text { Kerja }\end{array}$} & \multicolumn{2}{|c|}{ Kurang Baik } & \multicolumn{2}{|c|}{ Baik } & & & \\
\hline & & $\mathrm{N}$ & $\%$ & $\mathrm{~N}$ & $\%$ & $\mathrm{~N}$ & $\%$ & \multirow{4}{*}{0,020} \\
\hline 1. & Kurang Baik & 26 & 92,9 & 2 & 7,1 & 28 & 100 & \\
\hline \multirow[t]{2}{*}{2.} & Baik & 15 & 62,5 & 9 & 37,5 & 24 & 100 & \\
\hline & Total & 40 & 78,8 & 12 & 21,2 & 52 & 100 & \\
\hline
\end{tabular}

Hasil penelitian menunjukkan bahwa pelaksanaan program kesehatan dan keselamatan kerja bagian tambang kategori kurang baik sebanyak 28 responden $(53,8 \%)$, pada kategori ini karyawan bagian tambang yang kinerjanya kurang baik sebanyak 26 responden $(92,9 \%)$, dan kinerjanya baik sebanyak 2 responden $(7,1 \%)$. Pada kategori pelaksanaan program kesehatan dan keselamatan kerja bagian tambang kategori baik sebanyak 24 responden $(46,2 \%)$, kategori ini karyawan bagian tambang yang kinerjanya kurang baik sebanyak 15 responden $(62,5 \%)$, dan kinerjanya baik sebanyak 9 responden $(37,5 \%)$.

Hasil uji bivariat dengan menggunakan uji Chi-Square diperoleh nilai $\mathrm{P}$ value $=0,020$ pada taraf kepercayaan 5\% karena nilai $\mathrm{P}$ value $=0,020$ lebih kecil dari $0,05(0,020 \leq 0,05)$. Sehingga Ha diterima yang menyatakan ada hubungan antara pelaksanaan program kesehatan dan keselamatan kerja dengan kinerja karyawan bagian Tambang PT. Arteria Daya Mulia (ARIDA) Cirebon Tahun 2015.

\section{PEMBAHASAN}

\section{Pelaksanaan Program Kesehatan Dan Keselamatan Kerja}

Dalam penelitian ini didapatkan hasil pelaksanaan program kesehatan dan keselamatan kerja bahwa dari 52 responden terdapat 28 responden $(53,8 \%)$ yang menyatakan Pelaksanaan Program Kesehatan Dan Keselematan Kerja kurang baik, dan yang mengatakan Pelaksanaan Program Kesehatan Dan Keselematan Kerja baik terdapat 24 responden (46,2\%).

Berdasarkan hasil pengamatan di ruang produksi bagian Tambang PT. Arteria Daya Mulia (ARIDA) Cirebon pelaksanaan program kesehatan dan keselamatan kerja belum berjalan dengan maksimal sehingga lebih dari separuh responden menyatakan pelaksanaan program kesehatan dan keselamatan kerja kurang baik.

Program kesehatan dan keselamatan kerja adalah suatu sistem program yang dibuat bagi pekerja maupun pengusaha sebagai upaya pencegahan timbulnya kecelakaan kerja dan penyakit akibat hubungan kerja dalam lingkungan kerja dengan cara mengenali hal-hal yang berpotensi menimbulkan kecelakaan kerja serta tindakan antisipasi bila terjadi hal demikian. ${ }^{1}$

\section{Kinerja Karyawan}

Hasil penelitian menunjukkan bahwa dari 52 responden, terdapat 41 responden $(78,8 \%)$ yang kinerja kurang baik, dan yang kinerja baik terdapat 11 responden $(21,2 \%)$. Berdasarkan hasil pengamatan di ruang produksi bagian tambang PT. Arteria Daya Mulia (ARIDA) Cirebon kinerja karyawan secara kualitas dan kuantitas masih belum mencapai target produksi, berdasarkan data yang didapat pada tanggal 15 Juni 2015 menunjukkan bahwa hasil produksi bagian tambang perhari di seksi Extruder PE menghasilkan $4.440 \mathrm{Kg}$ tambang dari target $4.650 \mathrm{Kg}$ tambang perhari. Seksi twisting PE menghasilkan $1.150 \mathrm{Kg}$ tambang dari 
target $1.424 \mathrm{Kg}$ tambang perhari. Seksi tambang menghasilkan $1.933 \mathrm{Kg}$ tambang dari target $2.012 \mathrm{Kg}$ tambang perhari. ${ }^{3}$ Sehingga lebih dari separuh responden kinerjanya kurang baik.

Kinerja karyawan adalah perilaku nyata yang ditampilkan setiap orang sebagai prestasi kerja yang dihasilkan oleh karyawan sesuai dengan perannya dalam perusahaan. ${ }^{7}$

\section{Hubungan Pelaksanaan Program Kesehatan Dan Keselamatan Kerja Dengan Kinerja Karyawan}

Analisis bivariat dalam penelitian ini menggunakan rumus Chi-Square, menunjukkan bahwa pelaksanaan program kesehatan dan keselamatan kerja bagian Tambang kategori kurang baik sebanyak 28 responden $(53,8 \%)$, pada kategori ini karyawan bagian tambang yang kinerjanya kurang baik sebanyak 26 responden $(92,9 \%)$, dan kinerjanya baik sebanyak 2 responden $(7,1 \%)$. Pada kategori pelaksanaan program kesehatan dan keselamatan kerja bagian tambang kategori baik sebanyak 24 responden (46,2\%), kategori ini karyawan bagian tambang yang kinerjanya kurang baik sebanyak 15 responden $(62,5 \%)$, dan kinerjanya baik sebanyak 9 responden $(23,1 \%)$.

Hasil uji bivariat dengan menggunakan uji Chi-Square diperoleh nilai $\mathrm{P}$ value $=0,020$ pada taraf kepercayaan 5\% karena nilai $\mathrm{P}$ value $=0,020$ lebih kecil dari $0,05(0,020 \leq 0,05)$. Sehingga Ha diterima yang menyatakan ada hubungan antara pelaksanaan program kesehatan dan keselamatan kerja dengan kinerja karyawan bagian tambang PT. Arteria Daya Mulia (ARIDA) Cirebon Tahun 2015.

Dalam hal ini dapat disimpulkan pula bahwa terjadi kesamaan hasil dari penelitian yang dilakukan Arlin Riantiwi mengenai hubungan pelaksanaan program kesehatan dan keselamatan kerja terhadap peningkatan kinerja karyawan PT. PLN (Persero) distribusi Jawa Timur APJ XXX tahun 2009. Penelitian tersebut membatasi pengertian kinerja karyawan PLN XXX dalam konteks produktivitas kerja berkait dengan pelaksanaan program K3 yang diterapkan di lingkungan perusahaan. Maka hipotesis menunjukkan adanya hubungan antara pelaksanaan program kesehatan dan keselamatan kerja dengan tingkat produktivitas kinerja karyawan. Pelaksanaan program kesehatan dan keselamatan kerja sebagai variabel independen, tingkat produktivitas sebagai variabel dependen.

Selain itu menurut pendapat Mangkuprawira dan Vitayala (2007), kesehatan dan keselamatan kerja karyawan sangat berperan dalam mempengaruhi kinerja di perusahaan. Apabila kesehatan kerja terganggu dapat mengganggu mutu dan produktivitas kerja. ${ }^{8}$

Menurut Rivai (2004), karyawan memiliki hak untuk menuntut perusahaan agar menyediakan fasilitas kerja yang memadai agar keselamatan fisik dan mental mereka terlindungi dan dapat meningkatkan kinerja dari pekerjaan yang dilakukan. Selain itu juga jika perusahaan dapat menurunkan tingkat dan beratnya kecelakaan kerja, penyakit, dan hal-hal yang berkaitan dengan stress mampu meningkatkan kualitas kehidupan kerja para pekerjanya, maka perusahaan akan semakin efektif dan berdampak pada kinerja baik untuk perusahaan dan karyawan. ${ }^{9}$

Dari hasil penelitian tersebut, PT. Arteria Daya Mulia (ARIDA) Cirebon tahun 2015 pelaksanaan program kesehatan dan keselamatan kerja yang belum berjalan dengan maksimal berhubungan terhadap kinerja karyawan yang kurang baik. Berdasarkan penelitian pada sampel yang berjumlah 52 karyawan, ditemukan lebih dari separuh karyawan yang menyatakan pelaksanaan program kesehatan dan keselamatan kerja kurang baik, hal ini menyebabkan kinerja kurang baik pada karyawan bagian tambang di PT. Arteria Daya Mulia (ARIDA) Cirebon tahun 2015. Untuk menanggulangi pelaksanaan program kesehatan dan keselamatan kerja yang kurang baik PT. Arteria Daya Mulia (ARIDA) Cirebon harus meningkatkan program kesehatan dan keselamatan kerja terutama pada pengawasan, inspeksi sumber bahaya, dan penyediaan alat pelindung diri, agar karyawan merasa aman dan nyaman 
saat bekerja. Dalam hal ini peran serta dari manajer dan direktur perusahaan beserta jajarannya sangat diperlukan untuk membangun sebuah kebijakan yang bertujuan untuk meningkatkan pelaksanaan program kesehatan dan keselamatan kerja agar memberikan efek rasa aman dan nyaman kepada karyawan saat bekerja sehingga akan berpengaruh dalam menumbuhkembangkan kualitas dan kuantitas produksi, dan meningkatkan citra perusahaan.

\section{SIMPULAN}

1. Sebagian besar responden (53,8\%) yang menyatakan Pelaksanaan Program Kesehatan Dan Keselematan Kerja kurang baik di PT. Arteria Daya Mulia (ARIDA) Cirebon tahun 2015.

2. Hampir seluruhnya responden $(78,8 \%)$ memiliki kinerja yang kurang baik di PT. Arteria Daya Mulia (ARIDA) Cirebon tahun 2015.

3. Ada hubungan pelaksanaan program kesehatan dan keselamatan kerja dengan kinerja karyawan bagian tambang di PT. Arteria Daya Mulia (ARIDA) Cirebon tahun 2015.

\section{SARAN}

1. Untuk Peneliti

Perlu dilakukan penelitian lebih lanjut dengan sampel yang lebih besar, dengan waktu penelitian yang lebih lama agar mendapatkan hasil yang maksimal.

2. Untuk STIKes Cirebon

Hasil penelitian ini perlu dikembangkan dan dijadikan sebagai salah satu sumber untuk pengembangan ilmu dan pengetahuan mengenai pelaksanaan program kesehatan dan keselamatan kerja dengan kinerja karyawan yang lebih dalam sehingga dapat berguna khususnya bagi mahasiswa dan pembaca lainnya sebagai bahan pertimbangan bagi penelitian lain yang lebih luas.

3. Untuk PT. Arteria Daya Mulia (ARIDA) Cirebon

1) Mengadakan training pelatihan kesehatan dan keselamatan kerja karyawan secara rutin atau kontinu yang bekerjasama dengan pihak-pihak terkait baik swasta maupun pemerintah.

2) Memberikan pendidikan seperti penyuluhan mengenai sistem prosedur kerja, audit keselamatan, pemakaian alat pelindung diri, sistem inspeksi dan pemeliharaan peralatan.

3) Menyediakan alat pelindung diri menurut ketentuan batas waktu agar selalu dalam kondisi layak pakai sehingga dapat melindungi karyawan dan mencegah kejadian yang tidak diinginkan.

4) Meningkatkan waktu pengawasan dan pemantauan terhadap pelaksanaan program kesehatan dan keselamatan kerja.

5) Memberikan sanksi yang tegas kepada karyawan yang melanggar aturan-aturan kesehatan dan keselamatan kerja.

4. Untuk Karyawan PT. Arteria Daya Mulia (ARIDA) Cirebon

1) Selalu mengutamakan kesehatan dan keselamatan kerja.

2) Patuhi peraturan kesehatan dan keselamatan kerja.

3) Bekerja sesuai dengan standar operasional prosedur yang telah ditetapkan oleh perusahaan.

\section{DAFTAR PUSTAKA}

1. Fatahuddino. Pengaruh Program Keselamatan dan Kesehatan Kerja Terhadap Kepuasan Kerja Karyawan PT. PLN PLTU Barru; [diakses tanggal 11 Juni 2015]. Diunduh dari: http://fatahuddino5.blogspot.com

2. PT. Arteria Daya Mulia. Profil PT. Arteria Daya Mulia. Cirebon; 2015

3. PT. Arteria Daya Mulia. Buku Panduan Bagian Tambang. Cirebon;2015 
4. Catarina Cori P. P. Pengaruh kesehatan dan keselamatan kerja terhadap prestasi kerja karyawan pada PT. PLN (Persero) APJ Semarang. Purwokerto. Skripsi. Purwokerto : Universitas Diponegoro;2012

5. Eko Budiarto. Biostatistik untuk kedokteran dan kesehatan masyarakat. Jakarta: Buku Kedokteran EGC;2007

6. Soekidjo Notoatmodjo. Metodologi penelitian kesehatan. Jakarta: PT. Rineka Cipta; 2012.

7. Rivai,Veithzal. Manajemen sumber daya manusia untuk perusahaan. Jakarta: PT. Raja Grafindo;2004

8. Mangkuprawira,Vitayala. Manajemen mutu sumber daya manusia. Bogor:Ghalia Indonesia;2007

9. Cecep Dani Sucipto. Keselamatan dan kesehatan kerja. Yogyakarta. Gosyen;2014. 